\title{
A quick question on the Western dominance in the scientific literature
}

Minh-Hoang Nguyen

Ritsumeikan Asia Pacific University

Beppu, Oita 874-8577, Japan

Email: ng19m6tk@apu.ac.jp

January 8,2022

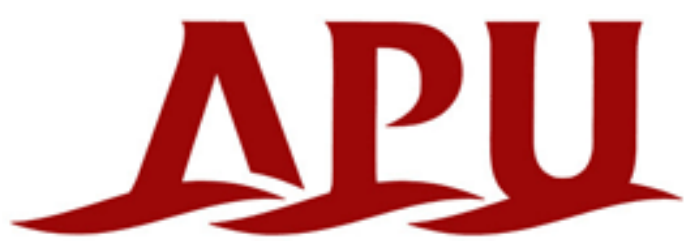

Ritsumeikan Asia Pacific University

$* * * * *$

Recently, I have noticed increasing media voices about the Western dominance over the world's scientific literature.

In late 2021, the article "Western monopoly of climate science is creating an eco-deficit culture" appeared on Economy, Land \& Climate Insight [1]. And in early January 2022, "Colonialism still influences the earth sciences today - and that's a big problem for research" was published on the Verge [2].

While I found the arguments and evidence convincing, I couldn't help thinking about the persistence of the problem. Thus, the following question, which is relevant to my research pursuit, arises:

Has the problem been created by the West's economic and military might?

I think the answer is yes, partly due to [3-4]. But I have not been able to decisively conclude it for now. But suppose that my gut feeling is correct, then another question is popping up:

Will China have the same dominance in the next 50 years?

\section{References}

[1] Vuong, Q. H. (2021). Western monopoly of climate science is creating an eco-deficit culture. Economy, Land \& Climate Insight. Retrieved from: https://elc- 
insight.org/western-monopoly-of-climate-science-is-creating-an-eco-deficitculture/

[2] Calma, J. (2022). Colonialism still influences the earth sciences today - and that's a big problem for research. The Verge. Retrieved from: https://www.theverge.com/2022/1/4/22865758/decolonizing-earth-sciencespaleontology-fossil-record

[3] Nguyen, M. H., \& Vuong, Q. H. (2021). Evaluation of the Aichi Biodiversity Targets: The international collaboration trilemma in interdisciplinary research. Pacific Conservation Biology, 28, doi:10.1071/PC21026.

[4] Vuong, Q. H. (2021). The semiconducting principle of monetary and environmental values exchange. Economics and Business Letters, 9(3), 284-290. 